\title{
Alternative Assessment Strategies and the Obstacles of their Application in Intermediate and Secondary Mathematics Courses in Hail City
}

\author{
Dr. Salman Sahud Raqi Alotaibi ,Assistant Professor, Department of Curriculum \& Teaching Methods, College \\ of Education in Al-Kharj, Prince Sattam bin Abdulaziz University, Al-Kharj - 11942, Saudi Arabia, \\ ss.alotaibi@psau.edu.sa
}

\begin{abstract}
The present study aimed at exposing the level of activation of alternative assessment strategies in teaching mathematics courses in the intermediate and secondary levels in Hail, and even to identify the obstacles that prevent their application. The study tool (the questionnaire) was designed after formulating the most important teaching practices related to the use of alternative evaluation and its skills in math's curricula. The most important obstacles that may reduce the adoption of alternative evaluation strategies in teaching mathematical content were also formulated, and hence identifying teachers' assessment of their reality. The sample of the study consisted of (70) mathematics teachers in the intermediate and secondary levels, during the second semester of the academic year $1441 \mathrm{AH}$. The results unfolded that the paper-andpencil evaluation method (tests, worksheets) is regarded the most popular with $84 \%$. Consequently, the two teaching practices are applied in a high way; urging students to progress in acquiring mathematical concepts and skills by varying assessment tools, and the teacher provides his students with several tasks that raise the value of mathematical understanding and apply what they have learned in similar contexts. Also, the most important hindrance facing teachers is the requirement of alternative assessment tools to be high dominated towards the levels of student acquisition and learning opportunities for mathematical concepts. Thus, the study recommended an increasing interest in alternative evaluation strategies, and activating its patterns and skills that can increase understanding and application of the components of mathematical content.
\end{abstract}

Keywords: Mathematics Development, Alternative Assessment Strategies, Teaching Evaluation.

Received: 06.12.2020 $\quad$ Accepted: 25.01.2021 $\quad$ Published: 03.02.2021

\section{INTRODUCTION}

a lot of educational systems rely on an improving the learning outcomes of their students, according to the latest tools and experiences that raise the credibility and scientificiality of the evaluation system in all mechanisms of the educational environment on the basis of an emphasis on the continuity of the evaluation, its proximity to the educational reality related to the student, its features, and its various capabilities. The concept of evaluation was obviously affected by modern educational developments, and hence it was reflected in the diversity of measurement tools and the multiplicity of their functions, as well as the expected performance targeted by the evaluation processes through which the individual differences and skills of students appear, according to modern strategies based on scientific methodology and foundations that focus on the truth and reality of what they have learned, in a manner that including the quality of the educational process and its outputs, in terms of the extent to which the learner reaches the learning objectives, and its ability and proficiency in them (Grisham-Brown, Hallam \& Brookshire, 2006). In light of the expansion and renewal of educational knowledge and experiences, and the emergence of a shift from behavioral theory to constructivist theory, the view regarding the purposes and objectives of educational evaluation has changed. So, it necessitated focusing on assessment for learning, instead of evaluating learning itself, and measuring what the learner knows which expresses the trend in its entirety with Authentic Assessment (Khanish, 2017; Ryan, 1994). It was clarified by (Madbouly, 2004) that Performance-based evaluation refers to that real evaluation in which tasks are defined, and the performance required to be accomplished in detail and even it allows the learner to observe while conducting the performance, applying and employing the knowledge he has learned, whether he learned it through direct achievement, or through constructive learning, which begins to establish new perceptions and relationships that link what he has learned from facts and concepts, 
and lead him to make sound decisions, and to overcome what it includes of the tasks required of the problems.

Moreover, the evaluation based on performance tests through which the learner demonstrates his learning by employing his skills in real life situations, situations that simulate real situations, or by making practical demonstrations that reveal the extent of his mastery of the skills and competencies he acquired on the basis of educational outcomes. Therefore, the evaluation of achievement and performance shifted in a successive scientific manner for the purpose of finding a kind of integration and balance between the various facets of student growth, developing his creative abilities and achieving his ambitions, and hence it was apparently reflected in the conscious field practices (Allam, 2009 \& Khatot, 2016). So, Changes in assessment occur by moving to more reliable evaluation methods, and scientific health in that means that the performance value in students' activities that are repeated must be related to the real world as closely as possible, and are no longer restricted to paper and pen, or electronic tests (Svinicki, 2004). Henceforth, with the multiple names and directions of the assessment, the real evaluation is called an alternative evaluation, or an evaluation of performance, by assigning the student to real educational tasks of direct feasibility, and marking according to the educational views with the realistic evaluation, and connected with meaningful learning (Abu Khalifa, 2017 \& Al Khalifa, 2019). An emphasis can be placed on employing these tasks and strategies in light of facilitating them to diagnose aspects of understanding and mastery of the dimensions of mathematical contents, which include real problems, and reinforce divergent thinking, which requires internal preparation on the part of the learner and clarity in evaluation tools and their diversity in order to achieve the mastery of current skills, and linking them to subsequent learning tests. So, the modern educational evaluation processes are based on the application of sophisticated methods to measure learner performance in general due to his knowledge and skills. So that, it focuses on the learner's acquisition of realistic practical experiences. Hence, Performance-based assessment is defined as a set of strategies that enhance the application of knowledge, skills and work habits through the learner's performance of certain tasks that he carries out in a practical way, related to real life and being meaningful to him (Brualdi, 1998).

Consequently, the performance tests are concerned with evaluating the performance skills of the learner in its various types including; mathematical problem-solving skills and laboratory skills, and hence it requires that the learner shows through them evidence indicating his awareness and acquisition of a correct understanding, and his clarification, proof and justification with examples about what he has learned leading meanwhile to his achievement of the indicators planned educationally (Mohammed \& Al-Khalifa, 2011 and Al-Harbi, 2014). Teachers face several interrelated processes that facilitate their making of educational decisions, the optimal use of education, the extent to which this affects the validity and reliability of evaluation results and the use of student results to improve and support their progress (Nitko \& Brookhart, 2011). Thus, the need to provide the requirements for the application of modern strategies in the teaching and evaluation processes renews and must be consistent with the components of the mathematical content, and reflected on their achievement on the basis of the educational stage, the depth and an order of knowledge. So, it is necessary to adopt practices that are based on the capabilities of the learner, his activity and readiness, and hence his interaction and self-interest in what is planned and designed for him which is a fundamental factor in achieving and acquiring educational experiences in scientific subjects, in which experiences vary between direct and deep.

The realistic evaluation gives great attention to the goals of the students' learning outcomes, which are in the form of performances or achievements reached by the learner as a result of the learning process which is linked to the student's life experiences realistically, and not merely to retrieve facts and information. Therefore, the performance-based assessment strategy requires the learner to demonstrate what he has learned through a work that provides indications of skill acquisition (Al-Fajal, 2016).

At the level of previous research and studies that dealt with alternative evaluation methods and strategies in teaching and learning mathematics, the study of Bin Omar and Al-Dawish (2020) aimed at uncovering the reality of mathematics teachers' use of alternative evaluation tools in Riyadh and to identify obstacles in their application. The survey sample reached (303) middle school mathematics teachers, and (24) educational supervisors on the basis of the prepared questionnaire. The study concluded that the rules of performance assessment and evaluation by written tests were the most used, and that the reality of teacher' use of alternative evaluation tools was in favor of evaluating by written tests, then achievement files from the viewpoint of the educational supervisors.

The Al-Omari (2020) experimental study also dealt with the effectiveness of using alternative evaluation strategies in the cognitive achievement of mathematics among female students of the first 
intermediate grade in Makkah Al-Mukarramah, and the intended study sample consisted of (47) students, divided into two groups, and the results exposed patently the superiority of the experimental group students in the dimensional application of the achievement test.

The study of Al-Saidi (2020) aimed at identifying the reality of the practice of mathematics teachers at the secondary level and their use of alternative assessment and tools. The sample included (96) male and female teachers of mathematics at the secondary level. The questionnaire was applied as a tool for the study, and hence it proved the existence of statistically significant differences between the arithmetic averages of the study sample responses depending on the variables (years of experience, academic qualification, training courses).

In the study of Al-Ruwaili and Al-Harbi (2019), which intended to determine the degree of practicing alternative evaluation strategies among mathematics teachers in Madinah in light of the curricula developed for the secondary stage, which numbered (130) female teachers. The study concluded that the practice of alternative evaluation strategies among mathematics teachers was average, with the statistically significant differences attributed to years of experience and training courses.

The study of Ghunaimat and Sabah (2017) revealed the degree to which mathematics teachers and teachers in the basic stage in Jordan used the patterns and tools of the performance-based evaluation strategy. So, the questionnaire designed for the purpose of the study includes (177) male and female teachers of mathematics. The results revealed that the demo style was the most used pattern whereas the least used pattern was the exhibitor pattern. Also, it disclosed that the numerical grading scale tool was the most used tool while the least used tool was the learning progress record.

Al-Asmari (2017) conducted a study concerned with determining the appropriate alternative evaluation strategies for learning mathematics in the middle stage, and the evaluation activities of each strategy. The descriptive survey sample consisted of mathematics curricula in the intermediate stage. Thus, the study concluded that the rates of inclusion in mathematics curricula for the activities of alternative evaluation strategies were varied. Hence, the observation strategy was the highest by $28 \%$ in the intermediate first grade curriculum, and that there is convergence, but unbalanced, in the level of inclusion of alternative evaluation activities for all strategies in mathematics curricula at the intermediate phase.

Al-olayan study (2015) intended to identify the reality of the use of mathematics teachers at the intermediate stage of alternative evaluation methods, and its relationship to the variables of the years of educational service and training courses. Its sample consisted of (68) mathematics teachers working in private schools in the intermediate phase in Riyadh, and the results uncovered that the degree of teachers' use of alternative evaluation methods was weak.

\section{Problem of the Study:}

In light of the educational renewals and innovations in the stream of mathematics curriculum development in the general education stages in the Kingdom of Saudi Arabia, according to the latest content developed through the McGraw-Hill series, there is a need to activate modern methods and strategies that are consistent with the philosophy of content and its components in terms of dependence on the learner, and his positivity in all teaching practices adopted by the school. Badawi (2003) pointed out that mathematics contains a set of mathematical skills that include performing a work in a variety of situations accurately without any mistakes; including performance skills, formality, qualitative, practicum, and quantitative requiring the availability of fit and appropriate evaluation tools and means so as to evaluate the degree of students' possession or mastery of those mathematical skills.

The results of the evaluation study for the development of mathematics and natural sciences project showed the importance of moving towards spreading the culture of evaluation for the sake of learning and not evaluating learning through focusing on the vitality of the learner in establishing his own knowledge and employment, his ability to apply multiple thinking skills and his possession of problem-solving and decisionmaking skills (Ministry Education, $1436 \mathrm{AH}$ ). Al-Hujaily's study (2016) also recommended the necessity of raising awareness of the concepts of alternative evaluation and the mechanism of using it in order to reinforce the importance of this trend in the development of teaching work.

According to the results of the participation of students of the Kingdom of Saudi Arabia who reached the age of fifteen in the study of the International Program for Student Assessment (PISA 2018), the average performance in mathematics reached (386), which is lower than the average score of countries in mathematics (OECD, 2020). So, it requires deep thinking regarding the nature of teaching and evaluation practices provided to the students and the extent of their impact on achieving educational competencies. 
An alternative evaluation is a comprehensive concept that seeks to measure capabilities and skills through the diversification of tests and tools, and the flexibility of educational tasks so as to suit the human phenomena revolving around the nature of learners, their psychological and developmental characteristics. It includes observing the performance and the amount of growth in the acquisition of scientific knowledge dimensions, the interpretation and analysis of progress results, and its reflection on behaviors and abilities. So, such procedure wouldn't be implemented unless by applying the tools that increase the value of learning. The idea of alternative evaluation is based on the belief that a student's learning and academic progress can be evaluated through actions and tasks that require active engagement like; researching and investigating complex problems, conducting field experiments, and high performance (Al-Sarraf, 2002).

It is good that there is a focus on variety and selection methods with regard to the nature of scientific courses and the complexity and widening of knowledge especially in the intermediate and secondary stages in which the learner begins to acquire abstract mathematical concepts through which it is necessary to activate the ideal use of modern evaluation strategies in order to ensure that the mathematical concepts and skills included in the lessons are measured. Al-olayan (2017) and Al-Saeedi (2020) studies recommended that mathematics teachers must adopt alternative evaluation strategies with providing educational plans and supportive training programs whereas in the other hand, Al-Asmari study (2017) called for finding a kind of balance in including alternative evaluation strategies in mathematics curricula.

Thus, the current study sought to determine the level of activation of alternative assessment strategies in teaching mathematics courses at the intermediate and secondary levels in Hail city and to identify the restrictions that ban their application.

\section{Questions of the Study:}

-What are the most important alternate evaluation strategies applied by mathematics teachers in the intermediate and secondary levels in Hail city?

- What is the level of teaching practices employed by mathematics teachers in the intermediate and secondary levels in Hail city in light of the alternate evaluation strategies?

-What are the most prominent hindrances to mathematics teachers' application of alternative assessment strategies in intermediate and secondary schools in Hail city?

\section{Objectives of the Study:}

The study intended to unfold the most important alternate evaluation strategies that are commonly used in teaching mathematics courses in the intermediate and secondary stages in Hail, determine their level of performance and indicate the most important obstacles that prevent their application of evaluation strategies and tools.

\section{Significance of the Study:}

The study got its importance due to its discussion for the field of evaluating the teaching work in mathematics courses in the intermediate and secondary levels. Also, it clarified the most important tools of alternative evaluation that teachers activate and will contribute to directing specialists and those interested in adopting alternative evaluation strategies, and informing the beneficiaries of their usefulness and importance. Moreover, the resent study proved the importance of very vital decisions in concern with evaluation practices and their consideration and improvement in relation to the components and dimensions of the developed mathematical content.

\section{Limitations of the Study:}

There is a set of limitations that may affect generalization of the study results as follows;

- The study was objectively limited to alternate evaluation strategies, tools, and teaching practices that are consistent with mathematics curricula.

- The study was humanly restricted to mathematics teachers at the intermediate and secondary levels in the city of Hail.

- The chronological scope or the duration of the study was limited to the second semester of the year $1441 \mathrm{AH}$.

- The study was spatially limited to intermediate and secondary governmental schools in Hail city. 


\section{Items of the Study:}

- An Alternative Evaluation: Jaber (2006) defined the alternative evaluation as the integration of students into meaningful, merit, and meaningful tasks, and hence it involves high-level thinking skills, interaction and harmonization of a wide range of knowledge. Consequently, it conveys to the students the meaning of doing their work well. So that the standards that are judged on its quality appear based on its light. Therefore, the evaluation will be determine a level and standard more than it is dependent on standardized assessment tools.

- $\quad$ The Researcher defines the alternative evaluation procedurally as the assessment that focuses on the student's performance in acquiring and learning mathematical concepts and skills, by diversifying the evaluation tasks and patterns, in a way that contributes to supporting his learning and employing his experiences in a meaningful way.

\section{Methods and Procedures of the Study:}

The study followed the descriptive survey approach, to investigate the extent of activation of alternative evaluation strategies and skills, and through it the hindrances that prevent the application of alternative evaluation in teaching work can be revealed. It can be carried out by a field contact with mathematics teachers, numbered (160) teachers in the intermediate and secondary phases, and the respondents with the study tool who reached (70) teachers.

Table. 1 Distribution of the Study Sample According to the Basic Variables

\begin{tabular}{|l|l|l|l|}
\hline \multirow{2}{*}{ Variable } & Educational Phase & Teaching Experience & $\begin{array}{l}\text { Has the teacher ever } \\
\text { enrolled in a training } \\
\text { course on the } \\
\text { application of } \\
\text { educational } \\
\text { assessment tools? }\end{array}$ \\
\cline { 2 - 5 } & $\begin{array}{l}\text { Intermediate } \\
\text { Secondary }\end{array}$ & $\begin{array}{l}\mathbf{1 - 5} \text { years 6-10 years 11 and } \\
\text { above years }\end{array}$ & Yes No \\
\hline $\begin{array}{l}\text { Mathematics } \\
\text { Teachers }\end{array}$ & 35 & $16 \quad 28 \quad 26$ & 48 \\
\hline
\end{tabular}

It is clear from Table (1) that the study sample was distributed equally between the intermediate and secondary educational levels, as the sample included in its entirety (70) teachers, whose teaching experience varied. The number of teachers whose experience was less than 5 years reached (16) teachers, while the number of teachers whose experience ranged from 6 to 10 years was (28) teachers, and (26) teachers whose experience exceeded 11 years. As well, $69 \%$ of the study sample enrolled in a training course is dealing with the application of educational evaluation tools.

The study tool represented in a questionnaire created to achieve the aims of the study, after reviewing the theoretical literature and previous studies that concentrated on alternative evaluation strategies and the need to integrate them into teaching practices. After judging and controlling the tool scientifically, it came in its final form in three main elements as the following:

1. A list of alternative evaluation strategies: It includes Presentation and Demonstration, Simulation and Debating, Paper and Pencil Calendar (Tests, Worksheets), Observation, Communicative Assessment (Interview, Group Work), Self-Review (Self-Assessment, Peer Assessment, Student Profile, Tasks and Projects), Checklists / Cross-out Lists, Ladders Assessment, Learning Progress Description Record, Storyline. Hence, the teachers are allowed to choose from any of the options provided, with the possibility that each mathematics teacher selects more than one style in case he adopts one strategy or more during his teaching work.

2. A list of the teaching practices that may be employed by mathematics teachers in the intermediate and secondary levels in Hail in light of the alternative evaluation strategies, and its number reached (15) indicators. The teachers patently determine the level of their application of these practices on the basis of the following triple ranking; (high, medium, low). 
3. A list of the most prominent obstacles that may ban teachers from applying alternative evaluation strategies, which totaled (9) indicators, and identifying the teachers' appreciation of them in terms of their importance as well as assessing the extent to which it is considered a hindrance to their employment of alternative evaluation strategies.

\section{Stability of the questionnaire phrases:}

Cronbach's Alpha coefficient was calculated to estimate the stability of the questionnaire expressions, after applying it to a questionnaire sample consisting of (21) teachers, and the value of the general stability coefficient was $(0.842)$, which is a positive value indicating that the study tool has a high degree of stability and is applicable. Then, after obtaining the official consent from the Education Department in Hail City, the study tool was applied in the field, and the questionnaire data were analyzed statistically through the SPSS statistical program, and the frequencies, percentages, weighted average and standard deviation were used for the sample estimates, according to each indicator.

\section{Study Results and Discussion:}

- The answer to the study's first question, which stated: what are the most important alternate evaluation strategies applied by mathematics teachers in the intermediate and secondary levels in Hail city?

Table (2) Alternative Assessment Strategies for Mathematics Teachers in Intermediate and Secondary Schools in Hail

\begin{tabular}{|c|c|c|c|}
\hline $\begin{array}{l}\text { Alternative assessment strategies used by mathematics } \\
\text { teachers in Intermediate and secondary school }\end{array}$ & Frequency & Rate & Rank \\
\hline Presentation and Demo & 29 & 41\% & 4 \\
\hline Simulation and Debating & 21 & $30 \%$ & 5 \\
\hline Paper and Pen Evaluation (tests, worksheets) & 59 & $84 \%$ & 1 \\
\hline Note & 32 & $46 \%$ & 3 \\
\hline Communicative assessment (interview, group work). & 36 & $\mathbf{5 1 \%}$ & 2 \\
\hline $\begin{array}{l}\text { Self-review (self-evaluation, peer evaluation, student file, tasks } \\
\text { and projects) }\end{array}$ & 29 & $41 \%$ & 4 \\
\hline Watch-lists / Write-offs & 17 & $24 \%$ & 6 \\
\hline Grading Scale Method & 7 & $10 \%$ & 8 \\
\hline Record of description of the learning progress & 10 & $14 \%$ & 7 \\
\hline Narrative record & 4 & $6 \%$ & 9 \\
\hline
\end{tabular}

It is evident from Table (2) that paper and pen assessment (tests, worksheets) is the most popular rate of $84 \%$ according to the estimate of the study sample, and this result is consistent with what Omar and Al-Dawish's study (2020) found in terms of the frequent use of written methods in evaluation work. Then, it is followed by the use of the communicative assessment (interview, group work) at a rate of 51\%, while the learning progress description record, the grading scale method, and the narrative record were the least popular in use. This result is consistent with the study of Ghunaimat and Sabah (2017), which exposed that the learning process strategy is the least practiced by teachers.

- The answer to the study's second question saying: What is the level of teaching practices employed by mathematics teachers in the intermediate and secondary levels in Hail city in light of the alternate evaluation strategies?

Table (3) The level of teaching practices employed by mathematics teachers in the intermediate and secondary levels in Hail city in light of the alternate evaluation strategies

\begin{tabular}{|l|l|l|l|l|l|l|}
\hline No. & Teaching Practices & \multicolumn{2}{|l|}{ Practice Level } & $\begin{array}{l}\text { Weighted } \\
\text { Average }\end{array}$ & $\begin{array}{l}\text { Standard } \\
\text { Deviation }\end{array}$ \\
\cline { 3 - 6 } & & High & Mid & Low & & $\mathbf{0 . 7 2}$ \\
\hline 1 & The teacher prepares a written plan at the & $\mathbf{4 1}$ & $\mathbf{2 1}$ & $\mathbf{9}$ & $\mathbf{2 . 4 4}$ & $\mathbf{0 . 7 4}$ \\
\hline
\end{tabular}




\begin{tabular}{|c|c|c|c|c|c|c|}
\hline & $\begin{array}{l}\text { beginning of each semester and informs his } \\
\text { students of it in order to agree on the } \\
\text { evaluation patterns that are commensurate } \\
\text { with their characteristics and abilities. }\end{array}$ & & & & high & \\
\hline 2 & $\begin{array}{l}\text { The teacher urges his students to progress in } \\
\text { acquiring mathematical concepts and skills by } \\
\text { diversifying assessment tools. }\end{array}$ & 44 & 23 & 3 & $\begin{array}{l}2.59 \\
\text { high }\end{array}$ & 0.58 \\
\hline 3 & $\begin{array}{l}\text { The teacher takes into account the individual } \\
\text { differences among his students by providing } \\
\text { them with tasks and issues that suit their } \\
\text { level and abilities. }\end{array}$ & 40 & 26 & 4 & $\begin{array}{l}2.51 \\
\text { high }\end{array}$ & 0.61 \\
\hline 4 & $\begin{array}{l}\text { The teacher increases his students' } \\
\text { effectiveness and desire to learn by focusing } \\
\text { on strategies that increase self-esteem. }\end{array}$ & 38 & 24 & 8 & $\begin{array}{l}2.43 \\
\text { mid }\end{array}$ & 0.70 \\
\hline 5 & $\begin{array}{l}\text { The teacher assists his students to evaluate } \\
\text { their learning of new mathematical } \\
\text { knowledge on their own which contributes to } \\
\text { knowing the areas of strength and weakness } \\
\text { and avoiding the later. }\end{array}$ & 30 & 30 & 10 & $\begin{array}{l}2.29 \\
\text { mid }\end{array}$ & 0.71 \\
\hline 6 & $\begin{array}{l}\text { The teacher uses an appropriate } \\
\text { configuration at the beginning of each } \\
\text { learning objective and hence ensuring that } \\
\text { students are ready and enthusiastic to } \\
\text { understand the mathematical content. }\end{array}$ & 41 & 22 & 7 & $\begin{array}{l}2.49 \\
\text { high }\end{array}$ & 0.68 \\
\hline 7 & $\begin{array}{l}\text { The teacher asks his students to express the } \\
\text { suitability of the assessment tool with which } \\
\text { they interact to measure learning. }\end{array}$ & 28 & 28 & 14 & $\begin{array}{l}2.20 \\
\text { mid }\end{array}$ & 0.76 \\
\hline 8 & $\begin{array}{l}\text { The teacher asks his students to review their } \\
\text { assignments that they have performed so as } \\
\text { to identify and adopt appropriate } \\
\text { improvement points. }\end{array}$ & 38 & 19 & 13 & $\begin{array}{l}2.36 \\
\text { high }\end{array}$ & 0.78 \\
\hline 9 & $\begin{array}{l}\text { The teacher provides his students with } \\
\text { instant feedback commensurate with the } \\
\text { process of building and acquiring } \\
\text { mathematical knowledge. }\end{array}$ & 39 & 23 & 8 & $\begin{array}{l}2.44 \\
\text { high }\end{array}$ & 0.69 \\
\hline 10 & $\begin{array}{l}\text { The teacher offers his students various tasks } \\
\text { that increase the value of mathematical } \\
\text { understanding and the application of what } \\
\text { they have learned in similar contexts. }\end{array}$ & 44 & 19 & 7 & $\begin{array}{l}32.5 \\
\text { high }\end{array}$ & 0.68 \\
\hline 11 & $\begin{array}{l}\text { The teacher assigns his students to prepare } \\
\text { experimental questions about mathematical } \\
\text { concepts that they have acquired and helps } \\
\text { them to improve and correct them. }\end{array}$ & 39 & 29 & 11 & $\begin{array}{l}2.40 \\
\text { high }\end{array}$ & 0.75 \\
\hline 12 & $\begin{array}{l}\text { The teacher discusses with his students what } \\
\text { kind of mathematical goals he wants them to } \\
\text { achieve in a participatory manner that } \\
\text { supports their learning. }\end{array}$ & 44 & 14 & 12 & $\begin{array}{l}2.46 \\
\text { high }\end{array}$ & 0.77 \\
\hline 13 & $\begin{array}{l}\text { The teacher balances the types of } \\
\text { mathematical tasks required of his students } \\
\text { inside and outside the teaching situation so as } \\
\text { to ensure the continuity of learning and } \\
\text { increase its acquisition. }\end{array}$ & 36 & 20 & 14 & $\begin{array}{l}2.31 \\
\text { mid }\end{array}$ & 0.79 \\
\hline 14 & $\begin{array}{l}\text { The teacher balances the areas of measuring } \\
\text { mathematical knowledge of his students, }\end{array}$ & 36 & 27 & 7 & $\begin{array}{l}2.41 \\
\text { high }\end{array}$ & 0.67 \\
\hline
\end{tabular}




\begin{tabular}{|l|l|l|l|l|l|l|}
\hline 15 & which helps them towards achieving it. & & & & & \\
\hline $\begin{array}{l}\text { The teacher directs his students to implement } \\
\text { group activities that increase the acquisition } \\
\text { of mathematical thinking skills included in the } \\
\text { course }\end{array}$ & $\mathbf{4 6}$ & $\mathbf{1 3}$ & $\mathbf{1 1}$ & $\begin{array}{l}\mathbf{2 . 5 0} \\
\text { high }\end{array}$ & $\mathbf{0 . 7 6}$ \\
\hline
\end{tabular}

It is apparent from Table (3) that the level of activation of mathematics teachers in the intermediate and secondary stages of alternative evaluation strategies was high, and its weighted average ranged between (2.20 - 2.59), and in its entirety it expresses the interest of the study sample in the stream of teaching practices that are consistent with alternative evaluation patterns and their supporting skills.

The two teaching practices occupied "The teacher urges his students to progress in acquiring mathematical concepts and skills through diversifying assessment tools," and "The teacher provides his students with various tasks that raise the value of mathematical understanding and the application of what they have learned in similar contexts," the highest level of application with an average of (2.59 and 2.53), respectively. Thus, these two practices enhance the functional value of the mathematics major in terms of the desire to verify the diversity of questions and their mastery, and even the repeated application of algorithms and mathematical rules in similar learning scales under the supervision of the teacher.

These results differ with the study of Al-Ruwaili and Al-Harbi (2019), and Al-Alyan (2015), each of which found a decrease in teaching practices that adopt alternative evaluation methods that may be attributed to teachers' conviction with these teaching practices, and that they are consistent with the nature of mathematical courses, the current construction philosophy that follows constructivist theory in learning, and the increase in student's effectiveness and participation in educational situations related to his environment and society and even to the foundations of previous learning.

The teaching practice stating "The teacher asks his students to express the suitability of the assessment tool with which they interacted to measure the level of learning" came with an average of (2.20), which is a value that reflects an average level of performance. Although it is a non-stressful exercise for the teacher, and does not put a burden on him, but he fears that they will be increasingly overlooked or forgotten, because the interest in the opinions of learners, especially in the intermediate and secondary stages, can be fulfilled through adopting dialogue and communication practices, and their discussion of evaluation mechanisms and forms, the extent of their influence and benefit from the conditions and goals of learning in mathematics courses and the suitability of a particular tool.

-The answer to the third question including "what are the most prominent hindrances to mathematics teachers' application of alternative assessment strategies in intermediate and secondary schools in Hail city?

Table (4) Obstacles of applying mathematics teachers to alternate evaluation strategies in intermediate and secondary schools in Hail

\begin{tabular}{|c|c|c|c|c|c|c|}
\hline \multirow[t]{2}{*}{ No. } & \multirow[t]{2}{*}{ Obstacles } & \multicolumn{3}{|c|}{ Significance Level } & \multirow{2}{*}{$\begin{array}{l}\text { Weighted } \\
\text { Average }\end{array}$} & \multirow{2}{*}{$\begin{array}{l}\text { Standard } \\
\text { Deviation }\end{array}$} \\
\hline & & High & Mid & Low & & \\
\hline 1 & $\begin{array}{l}\text { The need for alternative assessment tools to } \\
\text { be highly controlled to succeed the chances of } \\
\text { students acquisition and learning of } \\
\text { mathematical concepts. }\end{array}$ & 53 & 13 & 4 & $\begin{array}{l}2.70 \\
\text { high }\end{array}$ & 0.57 \\
\hline 2 & $\begin{array}{l}\text { The abundance and depth of mathematical } \\
\text { concepts and skills influence the choice of } \\
\text { some alternative evaluation tools but not } \\
\text { others. }\end{array}$ & 44 & 24 & 2 & $\begin{array}{l}2.60 \\
\text { high }\end{array}$ & 0.55 \\
\hline 3 & $\begin{array}{l}\text { The intermediate and high school students } \\
\text { are not aware of the dimensions of the } \\
\text { alternative evaluation that are compatible } \\
\text { with the complexity and expansion of } \\
\text { mathematical knowledge. }\end{array}$ & 38 & 19 & 13 & $\begin{array}{l}2.36 \\
\text { high }\end{array}$ & 0.78 \\
\hline
\end{tabular}




\begin{tabular}{|l|l|l|l|l|l|l|}
\hline 4 & $\begin{array}{l}\text { The lack of professional programs and } \\
\text { specialized workshops to enable teachers to } \\
\text { practice alternative assessment strategies. }\end{array}$ & $\mathbf{3 6}$ & $\mathbf{2 7}$ & $\mathbf{7}$ & $\begin{array}{l}\mathbf{2 . 4 1} \\
\text { high }\end{array}$ & $\mathbf{0 . 6 7}$ \\
\hline 5 & $\begin{array}{l}\text { The large number of students in each } \\
\text { classroom reduces the variety of alternative } \\
\text { assessment tools. }\end{array}$ & $\mathbf{4 2}$ & $\mathbf{2 0}$ & $\mathbf{8}$ & $\begin{array}{l}\mathbf{2 . 4 9} \\
\text { high }\end{array}$ & $\mathbf{0 . 7 0}$ \\
\hline 6 & $\begin{array}{l}\text { The need of some alternative tools for longer } \\
\text { time that is not compatible with the targeted } \\
\text { mathematical learning level. }\end{array}$ & $\mathbf{3 7}$ & $\mathbf{2 4}$ & $\mathbf{9}$ & $\begin{array}{l}\mathbf{2 . 4 0} \\
\text { high }\end{array}$ & $\mathbf{0 . 7 1}$ \\
\hline 7 & $\begin{array}{l}\text { The large number of tasks assigned to a } \\
\text { mathematics teacher forces him to choose } \\
\text { specific tools to evaluate his students } \\
\text { mathematical achievement. }\end{array}$ & $\mathbf{4 8}$ & $\mathbf{1 4}$ & $\mathbf{8}$ & $\begin{array}{l}\mathbf{2 . 5 7} \\
\text { high }\end{array}$ & $\mathbf{0 . 6 9}$ \\
\hline 8 & $\begin{array}{l}\text { The level of mathematical abilities of middle } \\
\text { and high school students requires direct tools } \\
\text { for evaluation. }\end{array}$ & $\mathbf{3 9}$ & $\mathbf{2 4}$ & $\mathbf{7}$ & $\begin{array}{l}\mathbf{2 . 4 6} \\
\text { high }\end{array}$ & $\mathbf{0 . 7 6}$ \\
\hline $\mathbf{9}$ & $\begin{array}{l}\text { The tendency of middle and high school } \\
\text { students to have direct evaluation patterns } \\
\text { when interacting with mathematical content, } \\
\text { and hence limiting the adoption of some } \\
\text { alternative evaluation tools. }\end{array}$ & $\mathbf{3 9}$ & $\mathbf{2 6}$ & $\mathbf{5}$ & $\begin{array}{l}\mathbf{2 . 4 9} \\
\text { high }\end{array}$ & $\mathbf{0 . 6 3}$ \\
\hline
\end{tabular}

It is obvious in Table (4) the most prominent obstacles to applying alternate evaluation strategies when teaching mathematics courses in the intermediate and secondary levels, and the level of appreciation of the study sample for its importance. So, all its indicators came to a degree of high importance and that confirms the need to take care of it and rectify what is related to it in order to ensure the application of modern strategies in mathematics courses, due to the conceptual nature of these curricula, which require proper planning of learning tools and tasks, and attention to the application of the optimal method on the basis of each lesson topic and students' characteristics as well as their previous learning level, which is related to the new lessons. The indicator stating "The need for alternative assessment tools to be highly controlled to succeed the chances of students' acquisition and learning of mathematical concepts" came to the highest according to the sample estimate, with an average of (2.70), followed by the indicator saying "The abundance and depth of mathematical concepts and skills influence the choice of some alternative evaluation tools but not others" with an average of (2.60).

Thus, when reflecting on the above-mentioned obstacles, it is necessary to carefully plan the establishment of training programs and mini-workshops that are concerned with increasing the empowerment of teachers to practice alternative assessment strategies, which directly contributes to accustoming teachers to the variety of tools and the different levels of measurement of the objectives. Hence, such thorough conduct apparently can qualify them to achieve good understanding, and increase their empowerment to measure the basic competencies that target students, and even their transfer to what helps in building their scientific personality, as well as providing them with the tools of science and mathematical knowledge.

\section{Recommendations:}

In the light of the present study results, the researcher strongly recommends the following:

1. Increasing an interest in alternative evaluation strategies, and activating its patterns and skills that rise the understanding and application of the components of mathematical content.

2. Participation in educating mathematics teachers on alternative assessment strategies, and training them in the optimal use of them on the basis of the nature of each educational stage.

3. Positing the possible solutions to avoid difficulties that ban the application and adoption of alternative evaluation strategies in teaching mathematical courses.

\section{References:}


Abu Khalifa, I. (2017). The Effect of Using the Performance-Based Evaluation Strategy on Acquiring the Skill of Building Achievement Tests among Students of the College of Educational Sciences and Arts. Educational Sciences Studies at the University of Jordan, Vol.44, No 1, pp.199-209.

Al Asmari, N. (2017). A Proposed Scenario for Developing an Evaluation of Mathematics Learning for Middle school in the Kingdom of Saudi Arabia in Light of Alternative Evaluation Strategies. Journal of Educational and Psychological Sciences, National Research Center, Gaza, Vol. 1, No. 10, pp. 60-94.

Al Khalifa, H. (2019). Self-Evaluation of Physical Education Teachers in Educational Stages in the Schools of the Ministry of Education in the Kingdom of Bahrain. Journal of Educational and Psychological Sciences: University of Bahrain, Vol. 20, No. 1, pp. 101-121.

Badawi, R. (2003). Strategies in Teaching and Evaluating Mathematics Learning. Jordan: Arab Thought House.

Jaber, J., A. (2006). Contemporary Trends and Experiences in Evaluating Student and Teacher Performance. Cairo: the Arab Thought House.

Al-Hujaily, M. (2016). The Degree of Satisfaction and Use of Teachers in the Kingdom of Saudi Arabia for Alternative Evaluation Methods to Assess the Teaching Process in Public Education and the Obstacles to Its use. Cairo University Journal of Educational Sciences, Vol. 24, No. 2, pp. 205-261.

Harahsheh, (2016). The Reality of Science Teachers' Use of Alternative Assessment Strategies and Tools in the Higher Basic Stage in Jordan. Al-Manara Journal for Research and Studies, Vol. 22, No. 4, pp. 341-372.

Al-Harbi, M. (2014). Realistic Academic Evaluation Strategies Based on Improving Multiple Skills in Educational Institutions. Journal of the Message of Education and Psychology, Vol. 44, pp. 49-80.

Hassan, I. (2012). The Reality of the Practice of Mathematics Teachers in the Elementary Stage of alternative Evaluation and Its relationship to their Beliefs about it. Arab Studies in Education and Psychology, Vol. 29, No.2, pp. 171-202.

Khatot, R. (2016). Educational Evaluation and Strategies. Al-Jami Journal of Psychological Studies and Educational Sciences in Algeria, pp. 103-119.

Khanish, Y. (2018). Educational Evaluation. Department of Psychology and Education: Publications of the Ministry of Higher Education and Scientific Research, Algeria.

Al-Ruwaili, A., and Al-Harbi, B. (2019). The Degree of Practicing Alternative Evaluation Strategies among Mathematics Teachers in Light of the Developed Curricula for the Secondary Stage in Madinah. Journal of Pedagogical Mathematics, Vol. 22, No. 9, pp. 88- 113.

Al-Shammari, E. (2018). A Proposed Visualization of a Training Program for Middle School Mathematics Teachers in Light of the Needs Associated with the Alternative Evaluation. The World of Education: The Arab Foundation for Scientific Consulting and Human Resource Development, Vol. 62, No. 1, pp. 173-217.

Al-Saraf, Q. (2002). Measurement and Evaluation in Education. Egypt: The Modern Book House.

Al-Saidi, M. (2020). The Reality of Mathematics Teachers' Practice of the Training Needs in the Use of Alternative Assessment Strategies and Tools. Journal of Pedagogical Mathematics, Vol. 23, No. 3, pp. 55- 99.

Al-Orabi, M. (2004). The Effectiveness of the Alternative Evaluation on Achievement, Communication and Reducing Mathematics Anxiety for Primary School Students. The Fourth Scientific Conference Mathematics of General Education in the Knowledge Society, Faculty of Education in Benha, the Egyptian Association of Mathematics Education, pp. 177-244.

Allam, S. (2006). Alternative Educational Evaluation: Its Theoretical Foundations and Field Applications. Cairo: The Arab Thought House.

Alawna, M. (2014). Training Needs in Alternative Assessment Strategies and Tools for Mathematics Teachers in the Directorate of Education in Nablus. An-Najah University Journal for Research - Humanities, Vol. 28, No. 11, pp. 2587-2618.

Al-Olayan, F. (2015). The Reality of Mathematics Teachers' Use of Alternative Evaluation methods in the Intermediate Phase from their Viewpoint. Journal of Education at Al-Azhar University, Vol. 164, No. 1, pp. 762-813.

Al-Olayan, F. (2017). Self-Evaluation of the Performance of Mathematics Teachers in Middle School in Light of the Standards of International School Mathematics Operations NCTM. Journal of Educational and Psychological Sciences at the University of Bahrain, Vol. 18, No. 1, pp. 549-593.

Omar, S., and Ad-Dawish, S. (2020). The Reality of Mathematics Teachers' Use of Alternative Assessment Tools in Middle School from their Viewpoint and the Educational Supervisors in Riyadh. Journal of Pedagogical Mathematics, Vol. 23, No. 3, pp. 240-308. 
Al-Omari, W. (2020). The Effectiveness of Using Alternative Assessment Strategies in Mathematics Achievement among First-Grade Intermediate Students. Reading and Knowledge Journal, Vol. 20, No. 224, pp. 227-260.

Ghneimat, M, and Sabah, S. (2017). The Degree to which Mathematics Teachers use the Performance-Based Assessment Strategy in the Primary Stage from the Teachers' Own Viewpoint. Educational Sciences Studies at the University of Jordan, Vol. 44, pp. 77-90.

Al-Fajal, S. (2016). Realistic Evaluation of Students' skill Performance between Reality and Expectations: An Evaluation Study. Journal of the Educational Association for Social Studies, Vol. 79, pp. 289-308.

Keita, J., and Ismail, M. (2017). The Degree to which Arabic Teachers use Realistic Assessment Strategies at the Secondary Level in Arab Schools in Mali. Journal of Educational Sciences at King Saud University, Vol. 29, No. 3, pp. 379-408.

Mohammad, K., and the Al-Khalifa, H. (2011). Educational Evaluation, Its Concept, Methods, Fields, and Modern Directions. 3rd ed, Riyadh: Al-Rashed Library.

Madbouly, M. (2004). Developing the Philosophical Fundamentals of Education Course in Light of the Philosophy of Performance-Based Evaluation: An Applied Study. Educational and Social Studies at Helwan University, Egypt, Vol. 10, No. 1, pp. 93-134.

OECD. (2020). Compiled Executive Summary of PISA Results, Retrieved on: 22nd September 2020, from: https://www.oecd.org/pisa/Combined Executive Summaries PISA 2018.pdf

Ministry of Education. (1436 AH). A Concise Report of the Evaluation Study of the Project to Develop Mathematics and Natural Sciences in Public education in the Kingdom of Saudi Arabia. Public Administration for Research and Studies. Retrieved on: September 18, 2020, from: https://departments.moe.gov.sa/StudyResearch/EducationalResearch/Lists/EducationalResearch/ Attachments/1/1651.pdf

Brualdi, A. (1999). Implementing Performance Assessment in the Classroom. Practical Assessment, Research \& Evaluation, Vol. 6, No. 2, pp. 1998-1999.

Grisham-Brown, J., Hallam, R., \& Brookshire, R. (2006). Using Authentic Assessment to Evidence Children's Progress toward Early Learning Standards. Early Childhood Education Journal, Vol. 34, No. 1, pp. 45-51.

Nitko, A. J., \& Brookhart, S. M. (2011). Educational Assessment of Students. 6th ed. Boston: Pearson

Ryan, C. D. (1994). Authentic Assessment, Professional's Guide. Teacher Created Materials, Inc., 6421 Industry Way, Westminster.

Svinicki, M. D. (2004). Authentic Assessment: Testing in Reality. New Directions for Teaching and Learning, Vol. 100, pp. 23-29. 